\title{
GAD65 vaccination: 5 years of follow-up in a randomised dose-escalating study in adult-onset autoimmune diabetes
}

\author{
C.-D. Agardh • K. F. Lynch • M. Palmér • K. Link • \\ Å. Lernmark
}

Received: 16 January 2009 / Accepted: 23 March 2009/Published online: 30 April 2009

(C) Springer-Verlag 2009

\begin{abstract}
Aims/hypothesis The aim of this study was to ascertain whether treatment of GAD65 autoantibody (GADA)-positive diabetic patients with alum-formulated recombinant GAD65 (GAD-alum) is safe and does not compromise beta cell function.

Methods This Phase 2, placebo-controlled, dose-escalation clinical trial, which was randomized through a central office, was performed in 47 GADA-positive type 2 diabetic patients, who received subcutaneous injections of GAD-alum $(4[n=9]$, $20[n=8], 100[n=9]$ or $500[n=8] \mu \mathrm{g})$ or placebo $(n=13)$ at weeks 1 and 4 of the trial. Participants and caregivers were blinded to group assignments. The primary outcome was safety as assessed by neurological tests, medications and beta cell function evaluated over 5 years, representing the end of the trial.

Results No severe study-related adverse events occurred during the 5 year follow-up. None of the dose groups was associated with an increased risk of starting insulin treatment compared with the placebo group. The use of oral hypoglycaemic agents did not differ between the dose groups. After 5 years, fasting C-peptide levels declined in the placebo group $\left(-0.24 ; 95 \% \mathrm{CI}-0.41\right.$ to $-0.07 \log _{10} \mathrm{nmol} / \mathrm{l}$;
\end{abstract}

Electronic supplementary material The online version of this article (doi:10.1007/s00125-009-1371-2) contains supplementary material, which is available to authorised users.

C.-D. Agardh $(\bowtie) \cdot$ K. F. Lynch $\cdot$ K. Link $\cdot$ A. Lernmark

Department of Endocrinology, University Hospital MAS,

SE-205 02 Malmö, Sweden

e-mail: carl-david.agardh@med.lu.se

M. Palmér

Department of Medicine, Karolinska Hospital,

Karolinska Institutet,

Stockholm, Sweden $p=0.01)$ and the $500 \mu \mathrm{g}$ dose group $(-0.37 ; 95 \% \mathrm{CI}-0.57$ to $\left.-0.17 \log _{10} \mathrm{nmol} / \mathrm{l} ; p=0.003\right)$, but not in the $4 \mu \mathrm{g}(-0.10$; $95 \% \mathrm{CI}-0.28$ to $\left.0.07 \log _{10} \mathrm{nmol} / \mathrm{l} ; p=0.20\right), 20 \mu \mathrm{g}(0.04$; $95 \% \mathrm{CI}-0.12$ to $\left.0.19 \log _{10} \mathrm{nmol} / \mathrm{l} ; p=0.58\right)$ and $100 \mu \mathrm{g}$ $\left(0.00 ; 95 \%\right.$ CI -0.20 to $\left.-0.20 \log _{10} \mathrm{nmol} / \mathrm{l} ; p=0.98\right)$ dose groups.

Conclusions/interpretation The primary outcome of safety was achieved, since no severe study-related adverse events occurred.

Trial registration Because the study was initiated before 1 July 2005, the protocol was not registered in a registry.

Funding This trial was funded by the National Institutes of Health (grant numbers DK26190 and DK53004), the Swedish Research Council (grant number 72X-14064) and Diamyd Therapeutics (Stockholm, Sweden).

Keywords Autoimmune diabetes - Beta cell function . GAD65 - Immunomodulation · Safety · Type 2 diabetes
Abbreviations
EMG Electromyography
GADA GAD65 autoantibody
IA-2A Insulinoma-associated antigen
IAA Insulin autoantibody
ICA Islet cell antibody
LADA Latent autoimmune diabetes in adults
SAE Serious adverse events

\section{Introduction}

Autoimmune destruction of pancreatic islet beta cells is the major cause of type 1 diabetes mellitus [1]. This destruction is associated with cellular and humoral immune responses 
to several beta cell autoantigens, both of which can precede clinical diagnosis of diabetes. In particular, GAD65 autoantibody (GADA), insulinoma-associated antigen (IA-2A) or insulin autoantibody (IAA) with or without islet cell antibodies (ICAs) precede clinical onset with $80-90 \%$ of patients with type 1 diabetes having one or several of these autoantibodies at the time of diagnosis [2]. The presence of all three islet autoantibodies, i.e. GADA, IA-2A and IAA, also predicts type 1 diabetes [3, 4]. In addition, these autoantibodies, especially GADA, occur in up to $10 \%$ of adults clinically presenting with type 2 diabetes. This patient group is often referred to as latent autoimmune diabetes in adults (LADA) [5]. The disease process in LADA patients is similar to that in type 1 diabetes in that they share HLA genetic susceptibility and autoantibodies associated with type 1 diabetes. However, in comparison to type 1 diabetes, insulin secretion is higher and the rate of progression to insulin dependency is slower in LADA patients [6].

We previously reported 24 week data for a Phase 2 study in LADA patients treated with recombinant human GAD65 formulated with aluminium hydroxide (GAD-alum; Diamyd Therapeutics, Stockholm, Sweden) [7]. The results showed that administration of GAD-alum in escalating dosages was safe and did not compromise beta cell function. We have now followed the 47 patients prospectively for 5 years to evaluate long-term clinical safety and dose level effects on beta cell function.

\section{Methods}

Participants and trial design The trial was designed as a randomised, double-blind, placebo-controlled, group comparison, dose-escalation study conducted in GADA-positive type 2 diabetic patients at the Department of Endocrinology, University Hospital MAS, Malmö and the Department of Medicine, St Görans Hospital, Stockholm, Sweden, as previously described in detail [7]. Randomisation was concealed by the clinical research organisation monitoring the study without any involvement by study investigators. Briefly, 47 patients were allocated to one of four groups receiving $4 \mu \mathrm{g}(n=9), 20 \mu \mathrm{g}(n=8), 100 \mu \mathrm{g}(n=9)$ or $500 \mu \mathrm{g}(n=8)$ of GAD-alum or placebo $(n=13)$. Sequential immunisation of each dose group was conducted after no safety issues had arisen at lower doses. Interim safety evaluation to approve dose escalation was conducted by a separate committee 4 weeks after the second GAD-alum injection. Nine patients in each group were planned to receive GAD-alum and three to receive placebo. A chart of participant flow through the study is presented in Electronic supplementary material (ESM) Fig. 1. The study was carried out according to the intent-to-treat principle. National regulatory and local ethics committee approvals were obtained for this study and written informed consent was obtained from participating individuals in accordance with the Declaration of Helsinki. Because the study was initiated before 1 July 2005, the protocol was not registered in a registry.

Patients were eligible to enter the trial if they fulfilled the following entry criteria at their first visit: (1) male or female patient aged 30 to 70 years; (2) diagnosed with type 2 diabetes within the previous 5 years; (3) presence of GADA; (4) diabetes treated only by diet, oral hypoglycaemic agents or both; (5) women of non child-bearing potential only; (6) absence of associated serious diseases or conditions that in the opinion of the investigators would exclude the patient from the trial; and (7) patients who had given written informed consent at the screening visit.

During the 5 year study period each patient was followed as an outpatient at regular intervals, with a total of 28 study visits during which islet autoantibodies, diabetes status, fasting lipids, haematological and biochemical variables were assessed and physical examinations, as well as the reporting of concomitant medication and adverse effects were undertaken. In total, 40/47 patients completed the 5 year study, which included information about adverse events. GADA and IA-2A were determined as previously described [8]. However, after 12 months, only GADA was analysed. Our laboratory is number 156 in the Diabetes Antibody Standardization Program for GADA and IA-2A [9]. Diabetes status assessment included fasting glucose, fasting and $2 \mathrm{~h}$ Sustacal-stimulated C-peptide, and $\mathrm{HbA}_{1 \mathrm{c}}$ for assessment of long-term metabolic control. Fasting C-peptide continued to be measured after patients started insulin treatment, while fasting glucose, stimulated $\mathrm{C}$-peptide and $\mathrm{HbA}_{1 \mathrm{c}}$ were no longer assessed in patients starting insulin treatment. In the patients without insulin treatment, fasting glucose, and fasting and $2 \mathrm{~h}$ Sustacal-stimulated C-peptide were measured at baseline then at 2, 6, 9 and 12 months, and thereafter every half year up to year $5 . \mathrm{HbA}_{1 \mathrm{c}}$ was similarly measured except that it started at 3 months. Blood samples for haematology were analysed for haemoglobin, erythrocyte count (including mean corpuscular volume and mean cell haemoglobin concentration) and packed cell volume, leucocyte cell count, differential white cell count and platelets. Biochemical variables analysed included plasma levels of glucose, C-peptide, $\mathrm{HbA}_{1 \mathrm{c}}$, urea, creatinine, phosphorus, total bilirubin, alkaline phosphatase, alanine transferase, glutamyl transferase, lactic dehydrogenase, amylase, albumin, C-reactive protein, total protein, and fasting lipid and lipoproteins. The criteria for the introduction of insulin treatment were left to the discretion of each attending physician. HLA was kindly determined by J.-X. She at the Center for Biotechnology and Genomic Medicine, Medical College of Georgia, Augusta, GA, USA as described previously [10]. Clinical neurological assessment and elec- 
tromyography (EMG) were performed at baseline and after 6 months to detect adverse effects on the neuromuscular system [11, 12]. Thereafter, a clinical neurological assessment was performed each year until the end of the study (month 60).

Test substances Diamyd Therapeutics provided sterile, prefilled vials of GAD-alum and placebo for clinical trial use [7]. Briefly, the unmodified recombinant form of human GAD65 was formulated with aluminium hydroxide. The GAD65 was manufactured using baculovirus/insect cell expression of the cDNA for recombinant human GAD65 [13]. Manufacture of the GAD-alum was performed under strict conditions of current Good Manufacturing Practice. Each vial contained a sterile formulation of 4, 20, 100 or $500 \mu \mathrm{g}$ of GAD65 in a constant amount of aluminium hydroxide. Coded vials containing an identical amount of aluminium hydroxide alone were used as placebo.

Statistical analysis Exact $\chi^{2}$ tests were used to examine for differences between the placebo and dose groups in the percentage of patients starting insulin treatment. A proportional hazard model tested for an increased risk of starting insulin treatment. Mean (SEM) absolute fasting $\log _{10} \mathrm{C}$-peptide levels were drawn using time plots. For each patient, we calculated the 5 year change in fasting $\log _{10}$ C-peptide levels from baseline and checked whether the changes in log values were normally distributed. One-sample $t$ tests were used to test whether mean changes differed from zero. Two-sample independent $t$ tests tested whether the mean change per dose group differed from placebo. Similar analyses were performed for $\mathrm{HbA}_{1 \mathrm{c}}$ and stimulated C-peptide in participants who had not started insulin treatment. All graphs were generated using GraphPad PRISM 4.0 (GraphPad Software, San Diego, CA, USA) and analyses performed using SPSS 14 (www.spss.com, accessed 31 March 2008).

\section{Results}

Diabetes markers in the placebo and dose groups On inspection, no important differences in baseline characteristics (high risk HLA, islet autoantibodies, BMI, LDL-cholesterol, HDL-cholesterol and triacylglycerol) were seen among the treatment and placebo participants (Table 1). Of the 47 patients, $20(43 \%)$ had the type 1 diabetes high-risk HLA DQ B1*0302 allele including 5/47 (11\%) with the high-risk $D Q B 1^{*} 0201 /$ *0302 genotype. Autoimmune diabetes was confirmed by the presence not only of GADA, which was an inclusion criteria, but also of ICAs in 33/47 (70\%) of the patients.

Table 1 Characteristics of autoimmune diabetes and other clinical variables in the patients at baseline

\begin{tabular}{|c|c|c|c|c|c|}
\hline \multirow[t]{2}{*}{ Diabetes marker } & \multirow[t]{2}{*}{ Placebo $(n=13)$} & \multicolumn{4}{|l|}{ GAD-alum } \\
\hline & & $4 \mu \mathrm{g}(n=9)$ & $20 \mu \mathrm{g}(n=8)$ & $100 \mu \mathrm{g}(n=9)$ & $500 \mu \mathrm{g}(n=8)$ \\
\hline $\mathrm{HbA}_{1 \mathrm{c}}(\%)$ & $5.9(4.7-7.4)$ & $6.7(5.5-10.9)$ & $5.9(5.1-9.9)$ & $6.0(4.6-7.1)$ & $5.9(5.4-8.1)$ \\
\hline Fasting C-peptide (nmol/l) & $0.7(0.3-1.7)$ & $0.6(0.3-1.5)$ & $0.7(0.5-1.4)$ & $0.7(0.3-1.5)$ & $0.6(0.3-1.8)$ \\
\hline Stimulated C-peptide (nmol/1) & $1.6(0.5-3.7)$ & $1.3(0.7-2.9)$ & $1.5(1.0-2.0)$ & $2.0(0.6-3.9)$ & $1.3(0.8-5.1)$ \\
\hline High-risk $H L A D Q B 1^{*} 0302$ & $4(31)$ & $3(33)$ & $4(50)$ & $5(56)$ & $4(50)$ \\
\hline \multicolumn{6}{|l|}{ Islet autoantibody positivity } \\
\hline GAD65 & $13(100)$ & $9(100)$ & $8(100)$ & $9(100)$ & $8(100)$ \\
\hline IA-2A & $1(8)$ & $0(0)$ & $2(25)$ & $1(11)$ & $1(13)$ \\
\hline IAA & $1(8)$ & $0(0)$ & $0(0)$ & $1(11)$ & $0(0)$ \\
\hline ICAs & $9(69)$ & $8(89)$ & $7(88)$ & $6(67)$ & $3(38)$ \\
\hline \multicolumn{6}{|l|}{ BMI } \\
\hline$<25 \mathrm{~kg} / \mathrm{m}^{2}$ & $2(15)$ & $4(44)$ & $2(25)$ & $4(44)$ & $3(37)$ \\
\hline$>25-30 \mathrm{~kg} / \mathrm{m}^{2}$ & $9(69)$ & $4(44)$ & $3(37)$ & $2(22)$ & $3(38)$ \\
\hline $\mathrm{t} 30 \mathrm{~kg} / \mathrm{m}^{2}$ & $2(15)$ & $1(11)$ & $3(37)$ & $3(33)$ & $2(25)$ \\
\hline $\mathrm{S}$ C-reactive protein $(\mathrm{mg} / \mathrm{l})$ & $9(5-12)$ & $9(9-10)$ & $9(9-9)$ & $9(5-15)$ & $5(5-9)$ \\
\hline $\mathrm{S} \operatorname{LDL}(\mathrm{mmol} / \mathrm{l})$ & $3.5(2.5-4.5)$ & $2.8(2.4-4.4)$ & $2.7(2.3-4.4)$ & $3.1(2.5-3.7)$ & $3.5(2.7-4.3)$ \\
\hline S HDL (mmol/l) & $1.3(0.7-1.5)$ & $1.1(0.7-1.6)$ & $1.0(0.9-1.6)$ & $1.3(0.9-1.9)$ & $1.2(0.7-2.0)$ \\
\hline S Triacylglycerol (mmol/l) & $1.1(0.4-10.0)$ & $0.8(0.4-2.6)$ & $1.3(0.5-2.5)$ & $1.1(0.7-2.5)$ & $1.1(0.6-3.5)$ \\
\hline B Haemoglobin (g/l) & $140(122-163)$ & $136(121-166)$ & $144(114-153)$ & $140(124-163)$ & $150(141-158)$ \\
\hline
\end{tabular}

Variables summarised as median (range) or $n(\%)$

B, whole blood; S, serum 
Table 2 Diabetes-related medications given to patients who were followed for 5 years
In total, 40 patients were followed for 5 years

${ }^{\text {a }}$ No patients were taking insulin at baseline

\begin{tabular}{|c|c|c|c|c|c|}
\hline \multirow[t]{2}{*}{ Medication } & \multirow[t]{2}{*}{ Placebo $(n=11)$} & \multicolumn{4}{|l|}{ GAD-alum } \\
\hline & & $4 \mu \mathrm{g}(n=7)$ & $20 \mu \mathrm{g}(n=7)$ & $100 \mu \mathrm{g}(n=7)$ & $500 \mu \mathrm{g}(n=8)$ \\
\hline \multicolumn{6}{|c|}{ Oral hypoglycaemic drugs } \\
\hline None & 2 & 1 & 0 & 0 & 0 \\
\hline 1 & 4 & 2 & 1 & 6 & 3 \\
\hline 2 & 5 & 2 & 3 & 1 & 4 \\
\hline$>2$ & 0 & 2 & 3 & 0 & 1 \\
\hline \multicolumn{6}{|l|}{ Insulin $^{\mathrm{a}}$} \\
\hline No & 4 & 2 & 6 & 6 & 3 \\
\hline Yes & 7 & 5 & 1 & 1 & 5 \\
\hline
\end{tabular}

Study-related adverse events There were 14 serious adverse events (SAE) in ten patients during the 5 year follow-up. Four of these patients were in the placebo group (six SAE), one was in the $20 \mu \mathrm{g}$ dose group (three SAE), two in the $100 \mu \mathrm{g}$ dose group (two SAE) and three in the $500 \mu \mathrm{g}$ dose group (three SAE). The SAE in the placebo group were: seizures, cholecystitis, myocardial infarction and cerebellar infarction leading to death in one patient, and subarachnoid bleeding and insulin treatment with hospitalisation due to cognitive dysfunction in one patient. The SAE in the $20 \mu \mathrm{g}$ group occurred in the same patient and were myocardial infarction and fractures of the fibula and malleoli. The SAE in the $100 \mu \mathrm{g}$ group were myocardial infarction and fracture of the left foot. The SAE in the $500 \mu \mathrm{g}$ group were transurethral resection of a malignant bladder tumour, osteoarthritis in the knee and prostate cancer. None of the SAE was considered to be treatment-related by the local investigators and were evaluated by the independent study safety committee. There were no abnormal neurological assessments by clinical examination or by EMG, which was used to detect adverse effects on the neuromuscular system.

Characteristics of patients who started insulin treatment The medications given at baseline and during follow-up (Table 2) indicate the use of various oral hypoglycaemic agents. Only seven patients were lost to follow-up.

None of the dose groups was associated with an increased risk of starting insulin treatment compared with the placebo group. Of the 40 patients who remained in the study, 19 started insulin treatment within 5 years of the prime dose being administered. Of these, ten (53\%) had low fasting C-peptide (lower quartile $<0.55 \mathrm{nmol} / \mathrm{l}$ ) at baseline.

Beta cell function among all patients followed for 5 years Over the time course, fasting C-peptide in the $20 \mu \mathrm{g}$ dose group increased significantly within the 1 st year compared with baseline and remained elevated (Fig. 1). Although not significant at 5 years compared with baseline, the increase in fasting C-peptide $(0.04 ; 95 \% \mathrm{CI}-0.12$ to $0.19 \log \mathrm{nmol} / \mathrm{l}$; $p=0.58)$ in this dose group was significantly greater $(0.28$; $0.04,0.51 \log \mathrm{nmol} / \mathrm{l} ; p=0.01)$ than in the placebo group (Fig. 1). Fasting C-peptide remained unchanged over time in the $100 \mu \mathrm{g}$ dose group $(0.00 ; 95 \% \mathrm{CI}-0.20$ to $0.20 \mathrm{log}$
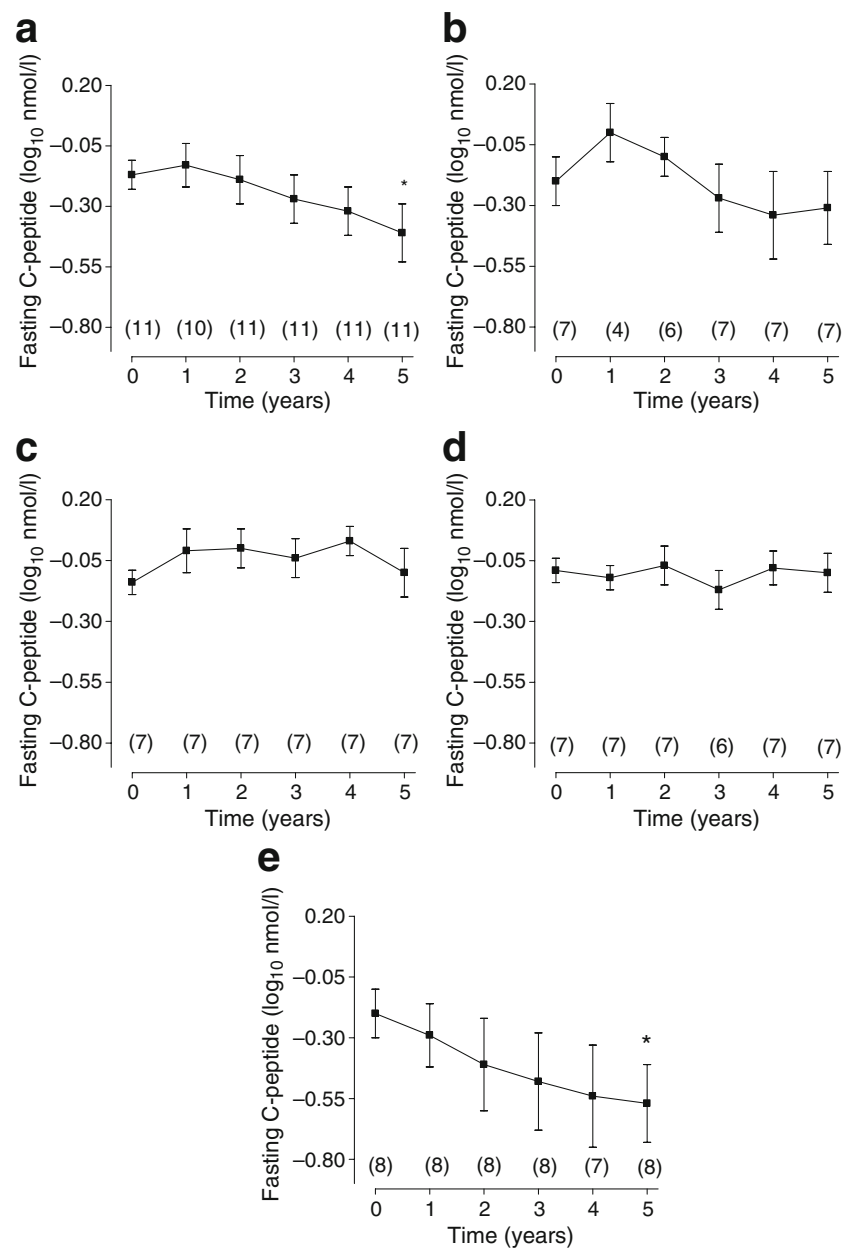

Fig. 1 Fasting C-peptide levels $(\log \mathrm{nmol} / \mathrm{l})$ when prime dose was administered (baseline) and at 1, 2, 3, 4 and 5 years thereafter in (a) placebo and (b) $4 \mu \mathrm{g}$, (c) $20 \mu \mathrm{g}$, (d) $100 \mu \mathrm{g}$ and (e) $500 \mu \mathrm{g}$ groups. Numbers in parentheses, patients $(n)$ for whom levels were available. Values are shown as mean \pm SEM. ${ }^{*} p<0.05$ at 5 years vs baseline 
nmol/1; $p=0.98)$. At 5 years, fasting $\mathrm{C}$-peptide levels showed a decline from baseline in the placebo group $(-0.24 ; 95 \% \mathrm{CI}$ -0.41 to $-0.07 \log \mathrm{nmol} / \mathrm{l} ; p=0.01$ ) (Fig. 1). In the $500 \mu \mathrm{g}$ dose group there was also a decline from baseline $(-0.37$; $95 \% \mathrm{CI}-0.57$ to $-0.17 \log \mathrm{nmol} / \mathrm{l} ; p=0.003$ ).

In the patients who were followed for 5 years (ESM Tables 1 and 2), the GAD-alum dose was significantly associated with the number of patients starting insulin treatment (placebo 7/11 [64\%]; $4 \mu \mathrm{g}$ group 5/7 [71\%]; $20 \mu \mathrm{g} \mathrm{1/7} \mathrm{[14 \% ];} 100 \mu \mathrm{g} \mathrm{1/7} \mathrm{[14 \% ];500 \mu g} \mathrm{5/8} \mathrm{[63 \% ];}$ $p=0.046$ ). The time until start of insulin treatment was not associated with any of the GAD-alum dose groups. However, patients receiving a 20 or $100 \mu \mathrm{g}$ dose had a reduced risk of starting insulin treatment (HR $0.29,95 \%$ CI 0.10 to $0.90 ; p=0.024$ ).

\section{Discussion}

The primary aim of this Phase 2 study was to evaluate whether alum-formulated recombinant human GAD65 given to LADA patients is safe and does not compromise beta cell function. The results confirm our previous report after 24 weeks [7] and extend to 5 years the clinical safety of GAD-alum and the finding that beta cell function was not compromised. The design of this trial was also meant to create potential hypotheses for testing in future trials. Our data suggest that the $20 \mu \mathrm{g}$ dose may be suitable for future clinical trials on safety and efficacy, since members of the $20 \mu \mathrm{g}$ dose group increased their fasting C-peptide over 5 years compared with placebo.

The LADA form of diabetes occurs in about $10 \%$ of patients classified as type 2 diabetes and not initially requiring insulin [14]. However, as demonstrated in the UKPDS study, about $80 \%$ of adult individuals with recently diagnosed type 2 diabetes and GADA and ICAs progressed to insulin requirements within 6 years, indicating the autoimmune nature of this condition and the progressive beta cell destruction associated with it [15]. At present no treatment modalities have been effective in halting this progression to insulin-requiring diabetes [16]. The approach described here, using alum-formulated GAD65 in an attempt to immunomodulate GADA-positive LADA patients, therefore represents a novel way of interrupting or slowing down the disease progression that leads to beta cell loss and insulin requirement.

In conclusion, our 5 year follow-up of the 47 LADA patients who were given GAD-alum at escalating dosages shows that the treatment was safe and did not compromise beta cell function. It should be noted that our study cannot reliably exclude rare $\mathrm{SAE}$ as a result of treatment with human recombinant GAD65. Larger trials are needed to address this unavoidable limitation of any small randomised trial. The increase in fasting and stimulated C-peptide levels that had previously been reported after 6 months in the group given $20 \mu \mathrm{g}$ was maintained during the 5 year follow-up. As there were no treatment-related SAE, further exploration of the immunomodulatory effects of $20 \mu \mathrm{g}$ GAD-alum is warranted.

Acknowledgements $\AA$. Lernmark was supported by the National Institutes of Health (grant numbers DK26190 and DK53004) and the Swedish Research Council (grant number 72X-14064). Diamyd Therapeutics, Stockholm, Sweden supported the study. The authors appreciate the technical support provided by G. Ahlqvist, H. Söderling, A. Kastensson, A. Nilsson, J. Ljungberg, C. Brundin and J. Arvastsson (all at the Department of Clinical Sciences, Lund University, University Hospital MAS, Malmö, Sweden).

Duality of interest K. F. Lynch previously provided statistical assistance for Diamyd Medical. The other authors declare that there is no duality of interest associated with this manuscript.

\section{References}

1. Gepts W (1965) Pathologic anatomy of the pancreas in juvenile diabetes mellitus. Diabetes 14:619-633

2. Graham J, Hagopian WA, Kockum I et al (2002) Diabetes incidence in Sweden study group; Swedish childhood diabetes study group: genetic effects on age-dependent onset and islet cell autoantibody markers in type 1 diabetes. Diabetes 51:13461355

3. Notkins AL, Lernmark $\AA$ (2002) Autoimmune type 1 diabetes: resolved and unresolved issues. J Clin Invest 108:1247-1252

4. Krischer JP, Cuthbertson DD, Yu L et al (2003) Screening strategies for the identification of multiple antibody-positive relatives of individuals with type 1 diabetes. J Clin Endocrinol Metab 88:103-108

5. Falorni A, Brozzetti A (2005) Diabetes-related antibodies in adult diabetic patients. Best Pract Res Clin Endocrinol Metab 19:119133

6. Tuomi T, Carlsson A, Li H et al (1999) Clinical and genetic characteristics of type 2 diabetes with and without GAD antibodies. Diabetes 48:150-157

7. Agardh C-D, Cilio CM, Lethagen ÅL et al (2005) Clinical evidence for the safety of GAD65 immunomodulation in adultonset autoimmune diabetes. J Diabetes Complications 19:238246

8. Lethagen ÅL, Ericsson UB, Hallengren B, Groop L, Tuomi T (2002) Glutamic acid decarboxylase antibody positivity is associated with an impaired insulin response to glucose and arginine in nondiabetic patients with autoimmune thyroiditis. J Clin Endocrinol Metab 87:1177-1183

9. Bingley PJ, Bonifacio E, Mueller PW (2003) Diabetes Antibody Standardization Program: first assay proficiency evaluation. Diabetes 52:1128-1136

10. Park YS, Wang CY, Ko KW et al (1998) Combinations of HLA DR and DQ molecules determine the susceptibility to insulindependent diabetes mellitus in Koreans. Hum Immunol 59:794780

11. Brown P, Rothwell JC, Marsden CD (1997) The stiff leg syndrome. J Neurol Neurosurg Psychiatr 62:31-37 
12. Barker RA, Revesz T, Thom M, Marsden CD, Brown P (1998) Review of 23 patients affected by the stiff man syndrome, stiff limb syndrome, and progressive encephalomyelitis with rigidity. $\mathrm{J}$ Neurol Neurosurg Psyciatr 65:640-663

13. Smith GE, Summers MD, Fraser MJ (1983) Production of human beta interferon in insect cells infected with baculovirus expression vector. Mol Cell Biol 3:2156-2165

14. Zimmet PZ, Tuomi T, Mackay IR et al (1994) Latent autoimmune diabetes mellitus in adults (LADA): the role of antibodies to glutamic acid decarboxylase in diagnosis and prediction of insulin dependency. Diabet Med 11:299-303

15. Turner R, Stratton I, Horton V et al (1997) Autoantibodies to islet-cell cytoplasm and glutamic acid decarboxylase for prediction of insulin requirement in type 2 diabetes. UK Prospective Diabetes Study (UKPDS). Lancet 350:12881293

16. Palmer J (2000) Therapeutic importance of subset of type 2 diabetes. Diabetes Care 23:574-575 